(C) 2009 The Author

Journal compilation (C) 2009 Metaphilosophy LLC and Blackwell Publishing Ltd

Published by Blackwell Publishing Ltd, 9600 Garsington Road, Oxford OX4 2DQ, UK, and

350 Main Street, Malden, MA 02148, USA

METAPHILOSOPHY

Vol. 40, Nos. 3-4, July 2009

0026-1068

\title{
THE THOUGHT AND TALK OF INDIVIDUALS WITH AUTISM: REFLECTIONS ON IAN HACKING
}

\author{
VICTORIA MCGEER
}

\begin{abstract}
Ian Hacking proposes that ways of talking about autistic experience can shape, or even transform, what it is like to be autistic. I explore the grounds for two nonexclusive interpretations of this thesis. The informative interpretation holds that, because nonautistics cannot read mental states into autistic behaviour as they normally do with one another, autistic self-narratives give nonautistics unique insights into what it is like to be autistic. This in turn affects how nonautistics interact with autistic individuals, enriching their social environment in various ways. The more radical, transformative interpretation holds that autistic experience is itself moulded under the influence of developing a language-game for talking about autistic experience. I endorse both theses, albeit with some cautionary remarks.
\end{abstract}

Keywords: autism, narrative, theory of mind, Kohler's phenomena, Vygotsky, form of life, folk-psychology, norms.

\section{The Clinical View Versus the Narrative View}

Individuals with autism are very much in the public eye. These days, anyone versed in the comings and goings of everyday culture will have heard of autism (and/or Asperger syndrome) ${ }^{1}$ - and doubtless knows something about it. Misconceptions also abound. But given that autism was only first described in the early 1940s (Asperger 1944; Kanner 1943), the subsequent development of clinical knowledge - and, with it, public awareness of the condition - has been quite remarkable. So remarkable, indeed, that certain clinical facts about autism are fairly well known-for example, that autism is a persisting neurodevelopmental disorder for which there currently is no cure; that it has a biological (and most likely genetic) basis, though environmental causes during foetal development

\footnotetext{
${ }^{1}$ Asperger syndrome is simply a milder form of autism, distinguished by no delay in language acquisition or in reasoning skills outside the social domain (Klin, Volkmar, and Sparrow 2000; Mayes, Calhoun, and Crites 2001; Mayes and Calhoun 2001; Ozonoff, South, and Miller 2000; Frith 2003). Henceforth, I will use the term "autism" nondiscrimately to cover Asperger syndrome as well.
} 
are not ruled out; that it manifests behaviourally in very early childhood (around eighteen months), though is probably present from birth and shapes the entire trajectory of an individual's development; that it is a "spectrum" disorder, affecting individuals to varying degrees - severe cases involving significant cognitive and behavioural disability, less severe cases allowing for adaptive functioning in many domains (such individuals are often diagnosed with Asperger syndrome); that even in severe cases, there can be islets of good, even superior, cognitive-perceptual ability-for example, so-called savant talents (though this is rare); and, finally, that despite significant variation in symptoms, as well as in developmental progress and outcome, individuals with autism share some notable features in common on the basis of which diagnosis is made - to wit, a qualitative impairment in reciprocal social interaction, a qualitative impairment in verbal and nonverbal communication, and a notably restricted repertoire of interests and activities (DSM-IV-TR; ICD-10). (Needless to say, this list of basic facts is provisional. It will no doubt be revised as understanding of the disorder progresses.)

These clinical features support the public image of a socially awkward, isolated, or uncommunicative human being, with idiosyncratic needs and interests, and a very poor-often debilitating - understanding of what other people are up to, or of the kind of mutual expectations that govern our myriad forms of interpersonal life. To what extent is this public image being augmented - or even transformed - by paying attention to what individuals with autism say about themselves? To what extent is autistic experience itself being augmented or transformed by finding public ways to talk about it? These are the questions Ian Hacking takes up in a recently published article in the Philosophical Transactions of the Royal Society. His aim there is to explore the ways in which autistic autobiographies - and, in general, self-report - are contributing to "the ongoing social and cultural evolution of the autistic spectrum," which evolution will have significant transformative effects on the lived experience of autistic individuals themselves (Hacking 2009a, 1467).

But why just autobiographical reports? As Hacking points out, these reports are but one thread in a much larger tapestry of what he calls "autistic narrative." In the past thirty years there has been an explosion of works bringing an entirely new genre into being: "not expert reports by clinicians or reflections by theorists, but stories about people with autism, told by the people themselves, or their families, or by novelists, or by writers of stories for children" (Hacking 2009a, 1467). Such narratives occur in a variety of media: printed matter, DVDs, blogs, YouTube postings, chat rooms, and other Internet formats. And they have a wide range of objectives: self-help, advocacy, information dissemination, pedagogy, creative expression, entertainment, and so on. Yet taken as a whole, the genre attests to the fact that autism has escaped the bounds of the subcultural. It is no longer a vaguely known clinical condition, like 
Fragile-X or Williams syndrome, but has features that are familiar, recognizable, portrayable - so much so that "characters" with autism are now appearing in fiction, assuming a place in the common stock of personalities that walk through the pages of make-believe, however highbrow or lowbrow these may be.

Could all this writing and talking about autism, by experts and nonexperts alike, contribute to how autism is experienced by autistic individuals themselves? Taken literally, the idea seems far-fetched. But as Hacking points out, the cross-germination between different kinds of writing should not be underestimated: "Different kinds of item influence each other in complex ways. Novelists study autobiographies, whose authors learn from theorists. Parents pick up ideas from novels when they are thinking about their children. We all watch movies and documentaries" (2009a, 1467). Hence, in his contribution to this collection, Hacking invites us to consider a more inclusive thesis growing out of his speculations on the transformative power of autistic autobiographies: "[T] he genre [of autistic narrative] is helping to bring into being an entire mode of discourse, cementing ways in which we have recently begun to talk, and will talk, about autism. It is developing a language, or, if you will, a new language game, one that is being created before our eyes and ears. This speech is, in turn, creating or extending a way for very unusual people - namely, autistic ones - to be, to exist, to live" (2009b).

In this short essay, I explore how Hacking's thesis could be true. I do so by focussing not on the larger genre of autism narrative but on the smaller subset consisting of autistic autobiographies and other forms of self-report. I begin here for a number of reasons. (1) Autistic selfnarratives are really at the epicentre of this phenomenon. While parents and other caregivers have written poignantly of their lived experiences with autistic individuals, it is the astonishing output of these individuals themselves that has really made an impact, both on the public imagination and on those who contribute to the genre of autism narrative from other perspectives. (2) Hacking has been deliberately inclusive in how he defines the genre of autistic narrative, including many fictional works that involve, through ignorance or creative licence, gross distortions of what autism is like. He rightly cautions about particular dangers that flow from the public dissemination of such misrepresentations, even in their milder forms-viz., that "neurotypicals" (this term for nonautistics comes from the autism community) will simply miss the "richness, the depth, and the difficulty of the phenomenon of autism" (2009b). Of course, this is a delicate issue for Hacking, since his thesis is that the phenomenon of autism is evolving precisely under the pressure of how we all talk about it. So in what sense can these works of fiction encourage "a false sense of what autism is really like" (2009b, my emphasis)? I do not see an explicit answer to this question in Hacking's essay. However, my hypothesis is that unless such representations actively engage those who have some 
first-hand experience with autism (including parents and caregivers, as well as autistic individuals themselves) - engage them, that is, by giving them a suggestive way of exploring their own experiences with autismsuch representations will be completely idle from the point of view of performing the shaping role that Hacking envisions (that doesn't mean they can't work mischief, the possibility he warns against). If this is right, then the core phenomenon is, once again, how autistic individuals come to think and talk about themselves. Hence, it's worth exploring Hacking's transformative thesis in this narrower domain. Finally (3) for the reason just given, it seems Hacking's more inclusive thesis cannot be true unless the narrower thesis is true. This makes it a good starting point for critical discussion.

\section{Informing Versus Transforming: Two Ways of Shaping the Autistic Spectrum}

So far I have distinguished between narrower and broader versions of Hacking's basic thesis, which holds that the genre of autistic narrative is contributing to the "the ongoing social and cultural evolution of the autistic spectrum." The narrower thesis focuses on the effects of autistic self-narratives, the broader thesis on the effects of narratives that are about, or at least involve, autistic individuals. My immediate interest, as I have said, is in the narrower thesis, but the point I am about to make could apply to the broader thesis as well (though I'll not explore that possibility here).

There are two ways in which autistic self-narratives could have an impact on how autism is conceputalized and on how it is experienced. These ways are not mutually exclusive - indeed, I think Hacking has both in mind. However, the first way - which I call "informative" - is perhaps less controversial. This includes, for instance, giving nonautistic people or neurotypicals (whether they're parents, teachers, therapists, clinicians, academic psychologists, or simply members of the lay public) better insight into the subjective world of autistic individuals - so that they come to understand them as "thick," rather than "thin," people (to use Hacking's apt metaphor). It would also include giving autistic people themselves information that there are others out there like them, others with whom they may be able to connect (via the Internet and other forms of autism-friendly communication-Hacking mentions "texting" as an example) for purposes of friendship, information exchange, self-advocacy, and so on.

The second aspect of Hacking's proposal is perhaps more controversial; it's certainly more dramatic. It's that this relatively new and thriving genre of autistic self-narration has the power to transform how the autistic spectrum is constituted - as Hacking says - both "for those who inhabit [it] ... and for those who do not" $(2009 \mathrm{a}, 1467)$. The idea is that these self- 
narrations not only tell the nonautistic how autistic people experience their lives and the world around them but also help to create a framework, or "form of life," in terms of which their individual lives will be experienced - differently, as it may be, from how they would be experienced if this framework were not in place. I am attracted to this transformative thesis, but I also have questions about it, including how precisely to interpret it. I return to this issue later in the essay. However, there is much to be said even about the less controversial aspect of Hacking's proposal, so I begin here: with the idea that autistic selfnarratives can have a critical informative impact on how to understand individuals within the autism spectrum.

\section{From Thin People to Thick People}

These narratives have been-indeed, still are-regarded as amazing, even shocking (as Oliver Sacks says), given various assumptions that have prevailed about autism even among those who as parents, caregivers, and clinicians have the most familiarity with autistic individuals: assumptions about the "thinness" of their mental lives, supposedly consequent on their relative lack of self-conscious, reflective, and imaginative capacities. But how did neurotypicals form this mistaken impression of autistic subjective "thinness"?

There are, I think, two important sources of this mistaken impression, one more basic or "intuitive" and the other more "theoretical." Hacking focuses on the more basic, intuitive source of this impression by calling attention to what he terms "Köhler's phenomena," invoking the insight of Gestalt psychologist Wolfgang Köhler (Hacking 2009b; for more detail, see Hacking 2009a, 1470-71). This is such an important idea, it's worth dwelling on - and will lead, in any case, to my identifying what may be an important contributing factor to the mistaken impression of autistic subjective thinness: viz., the theoretical commitment that many cognitive psychologists have to a "theory of mind" deficit account of autistic social difficulties. Hacking himself professes no great enthusiasm for this approach, preferring instead a Vygotskian account of how we come to think of other people as having complex internal states (2009b). To my mind, however, there are dangers to the theory of mind approach that are not sufficiently highlighted in Hacking's passing remarks, so I shall try to make these more explicit. But first let me turn to Kohler's phenomena.

Hacking rightly emphasizes an absolutely basic feature of our perception of other people, which he calls Kohler's phenomena (see too McGeer forthcoming): that, in many typical contexts, we don't infer the moods, thoughts, feelings, or intentions of others, we simply see such subjective or mental phenomena-such ways of being minded-directly in their behaviour, in the way they conduct themselves in relation to us or to other aspects of the world around them. We see it in their expressions, their 
gestures, their movements - and here Hacking gives some nice examples: seeing that a child wants to touch the dog, but doesn't dare; seeing that someone's upset at having to do a task he's just been assigned; seeing that someone's reluctant to keep a promise she's made.

Now this proclivity we have for seeing aspects of mind in everyday actions and expressions is so effortless and automatic that we even experience Kohler's phenomena in places where we know that no minds are really present at all. This was nicely demonstrated by the psychologists Heider and Simmel in a simple experiment they conducted in the 1940s (Heider and Simmel 1944). They showed college students a short animated film (approximately ninety seconds long) of three geometric figures - two triangles and a circle - moving in and around a rectangular enclosure in a two-dimensional space (figure 1), and asked their subjects to describe what they saw. ${ }^{2}$ The vast majority of viewers - thirty-four out of thirty-five subjects in the original experiment - are irresistibly drawn to describe these movements in anthropomorphic terms. In fact, ordinary viewers are overwhelmingly consistent in their interpretations, perceiving in this film a stirring little drama involving two friends, one of which - a young Galahad - bravely tries to protect his small and terrified companion from the threatening attacks of a large and angry bully. There are a few close calls, but the story ends happily enough with our two friends trapping the nasty bully, delighting in their success, and making good their escape.

So what does this experiment demonstrate? That, for ordinary viewers, certain perceptual configurations (in this case, movements of figures in space in particular relations to one another) are sufficient to convey information of a specifically social —indeed, mentalistic — kind. But not so for individuals with autism; and this is true even if they are capable of passing quite sophisticated theory of mind tests, tests that are geared to measure their capacity to attribute and reason about others' mental states. In a recent study, the psychologist Ami Kin showed this film to a group of such high-functioning individuals and found that they did not produce the spontaneous social narratives so robustly offered by typical viewers. Indeed, if they used any mental state terminology at all (and many didn't), they did so infrequently and in a way that was often irrelevant to the social plot ordinarily discerned in the film (Klin 2000). In other words, these individuals failed to experience the Kohler's phenomena so evident to ordinary viewers.

Now we come to the key question: What explains the neurotypical's proclivity to experience Kohler's phenomena, both in everyday contexts and in these artificial circumstances designed to reveal the basic percep-

${ }^{2}$ The original Heider and Simmel animation can now be viewed on YouTube. Similar demonstrations are readily available on the Web by searching "Heider Simmel animation" (or demonstration). 


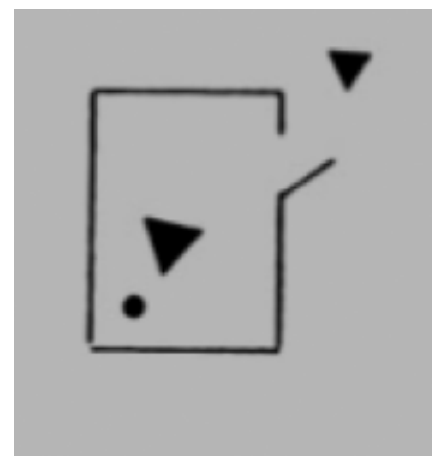

FIGURE 1. Still image from Heider and Simmel (1944) film clip

tual cues to which we're normally responding? More importantly for present purposes, what explains the absence of this proclivity in individuals with autism?

\section{Two Hypotheses: "Theory of Mind" Versus "Form of Life"}

The currently popular view among cognitive psychologists is that neurotypicals have a modularised (possibly innate) capacity for seeing others as possessing mental states, which states predict and explain their behaviour in systematic ways. This is the famed theory of mind (or ToM) hypothesis. Autistic individuals are said to have a ToM deficit-damage or dysfunction to this modularised system. And this explains why they are insusceptible to Kohler's phenomena, both in everyday contexts and with respect to the kinds of artificial stimuli created by Heider and Simmel. Now, as I've said, Hacking does not show any real enthusiasm for this view; indeed, he argues that the ToM approach "does not easily distinguish between, on the one hand, seeing what someone is doing right off and, on the other, inferring or working it out from clues" (2009a, 1470). It's worth pointing out, however, that ToM advocates do not see their approach as requiring explicit inferential processes. For many, this is the point of hypothesizing a ToM module: it performs its computations subpersonally, allowing those who possess such a module to see right off what others are "thinking, feeling, plotting, and so forth." If the ToM approach is off base, at least in this modular version, it must be for other reasons. Here I shall suggest two considerations that militate against it.

The first consideration is not compelling; still, I think it is worth noting. The ToM deficit hypothesis is supposed to explain why individuals with autism are insusceptible to Kohler's phenomena, including those that are robustly, if artificially, generated by the Heider and Simmel film. But the high-functioning individuals in Klin's study did not have a ToM deficit, at 
least as this is standardly tested and is standardly understood - namely, as a capacity to make mental state attributions for the purpose of explaining and predicting the behaviour of others. Recall that these individuals were quite capable of passing ToM tests (for example, a variety of false belief tasks). So ToM advocates must account for this dissociation. One possibility is that such high-functioning individuals do not pass ToM tests in the normal subpersonal way-that is, by grace of a properly functioning ToM module. Rather, they must rely on some explicit process of reasoning, something more like genuine theorizing, which is unlikely to be triggered by the kind of low-level perceptual cues present in the Heider and Simmel animation. In other words, the Klin study does not refute the ToM deficit hypothesis - indeed, it might be taken to argue in its favour, at least in its modular version.

A second consideration is far more compelling (for further discussion, see McGeer 2001). The ToM deficit hypothesis implies that the autistic inability to experience Kohler's phenomena is a disability unique to them, consequent on damage or dysfunction to their mind-reading system. But as Hacking points out, there's a crucial symmetry here: we do not experience any Kohler's phenomena in our interaction with autistic individuals any more than they experience such phenomena in their interactions with us. We do not directly perceive their subjective experiences as expressed in their behaviour any more than they perceive ours. They are blind to our minds, but so too are we blind to theirs. The ToM deficit hypothesis, by putting all the disability on the autistic side of the divide, does not seem to have the resources to explain why this should be the case. So we need an alternative hypothesis: call it the "form of life" hypothesis. (I take what follows to be roughly Hacking's view-and it's one I've defended myself, calling it, less elegantly, the "psycho-praxis" hypothesis [see McGeer 2001 and forthcoming].)

According to the form of life hypothesis, Kohler's phenomena are to be explained as a species of skilled perception that arises in conjunction with skilled performance in any norm-governed shared practice, or form of life. Consider a mundane example: learning how to play chess. In the beginning, the novice will make moves that mostly conform to the rules, although she may need some instruction in this. She knows what her objective is - to take the other's king and protect her own — but, not being very adept at making moves herself, she'll have little capacity to understand what her opponent is up to, and will mostly fail to perceive dangerous situations. But as her skill improves, she'll be able to strategize more effectively, and simultaneously she'll be better able to perceive her opponent's strategies as these unfold on the board in front of her. And if she persists in the practice, exposing herself to more matches and more styles of play, her performance will improve still further, encompassing both her ability to produce novel and interesting moves herself and her ability to perceive virtuoso play in the actions of others. As Gilbert Ryle 
so persuasively observed, skilled performance and skilled perception are two sides of the same coin (Ryle 1949).

Now consider the various social practices that make up what might loosely be called our "folk-psychology" - practices through which we regulate, share, or disguise our thoughts and feelings in order, among many other things, to ease or intensify social situations, to manipulate others to get what we want, to convey our faith or trust in them so as to encourage confidence in their own powers, to assure them of our dependability or our friendship. These practices, varied and complex though they may be, are deeply norm-governed. Take, for instance, what's involved in being a friend. Friends don't let each other down without good reason; they don't say malicious things behind one another's backs; they go beyond the call of duty for certain extraordinary demands; they laugh at one another's jokes (even if they're not very funny); they try to be honest with one another when it really counts; and so on. Anyone who's skilled in the practice of being a friend understands these things, and regulates himself accordingly, depending on the level of friendship he hopes to sustain in a particular relationship. Equally, anyone who's skilled in the practice of being a friend, recognizes when others are, through their actions and expressions, either trying to adhere to the norms of friendship, only paying lip service to these norms, or actively showing a disinterest in observing them.

How do we learn to be a friend - or, indeed, to be effective and skilled participants in the myriad complex practices through which we regulate, share, or disguise our thoughts and feelings in interaction with others? There's an elaborate developmental story to be told here, to be sure-one that psychologists are slowly beginning to unravel. But it's clear that our training in these folk-psychological practices begins in early infancy, as parents and other caregivers progressively scaffold our entry into more and more complex interactions that, thanks to them, bear the normative shape of recognizable social forms. Our thoughts and feelings develop likewise as we learn to form and regulate our own qualities of mind in ways commensurate with those of a "normal psychological agent" in the context of such interactions. There is, of course, plenty of room for play and manoeuvre, as there is in chess; but basic normative structures must be in place in all these varied practices if we are to make sense of one another's actions and expressions; if we're to share a form of life. That we experience Kohler's phenomena in interactions with one another is just the predictable outcome of our becoming skilled in the myriad practices that constitute our shared form of life.

Where does this leave autistic individuals? According to the form of life hypothesis, they are simply not skilled in the myriad practices that constitute our shared folk-psychological expertise. And why is this? Again, there will be a complicated developmental story to be told, one that reaches back into early infancy and identifies factors, both endogen- 
ous and exogenous, that disable autistic individuals from having their minds and actions moulded under the regulative regime of parental scaffolding. Hence, they will not become typical, recognizable psychological agents. They will not experience Kohler's phenomena in their interactions with us, and we - of course - will not experience Kohler's phenomena in our interactions with them.

But now, given that we do not experience Kohler's phenomena in relation to autistic individuals, they are bound to seem subjectively thin to us, as if they do not have complex or well-developed qualities of mind. This is one of Hacking's critical points. Moreover, this intuitive impression is likely to be considerably bolstered if we reflect on the fact that typical children only develop sophisticated qualities of mind, as they acquire language, through the continual give and take of regulative parental scaffolding - scaffolding that brings them into a communal language and a shared way of being minded. Thus, to be minded at all seems, for neurotypicals at any rate, to be irreducibly co-minded. So, how could autistic individuals develop any complex qualities of mind without participating in this shared practice?

Well, of course, autistic children do not grow up in utter isolation from other human beings. They are not, in that sense, deprived of parental scaffolding. Indeed, there are legion accounts, both heart-breaking and heart-warming, of continuous and exhausting effort on the part of parents, teachers, therapists, and caregivers to break through the barriers of autistic isolation and idiosyncrasy. And, of course, we now have many accounts from autistic individuals themselves of their equally heroic efforts to make sense and order out of a disturbed and disturbing universe. So somehow in this combined effort of insistent social and linguistic training, on the one side, coupled with the insistent need for routines, clear rules, soothing stereotypies, and other forms of environmentally managed sensory regulation, many autistic individuals develop extraordinary qualities of mind, even if some of these qualities of mind (some of their experiences, thoughts, and emotions) are strange and idiosyncratic and sometimes barely comprehensible to those of us who follow a more ordinary developmental trajectory.

And how do we know this? Well, as Hacking has argued, it certainly hasn't been, and indeed can't be, through reading their behaviour. This is just what we would expect if the form of life hypothesis is correct. So our only means of discerning the surprising fact that autistic individuals have much richer subjectivities than we might have thought possible is through their self-narratives. These narratives provide both an existence proof that their form of idiosyncratic linguistic and psychological development is possible and also gives us our best means of accessing what these minds, so differently developed from our own, can be like. Of course, such autistic narratives are likely to be odd and idiosyncratic and difficult to understand. And this is not just because the minds therein displayed are 
so unusual from a nonautistic perspective; it's also because the language available to display those minds is still our (nonautistic) communal language, a language geared, for the most part, to typical psychological experiences. As Hacking points out, autistic individuals will have their work cut out for them to adapt, manipulate, and perhaps outright distort the common meanings of our words in order to convey something of their own subjective experience. So we should be prepared for semantic oddities - and be prepared to accept as well that the experiences so conveyed may themselves shift and change under pressure from the language used to express them. I'll get to this possibility in a moment.

For now, let me simply agree with Hacking that this new and thriving genre of autistic self-narrative has a vital informative role to play in compensating, as he says, for the absence of Kohler's phenomena in the interactions between autistic and nonautistic people. This role makes sense if the form of life hypothesis is the right way to understand the disconnection between those with autism and those without it. But what can be said under the alternative hypothesis - that autistic individuals fail to understand neurotypical individuals because they suffer a ToM deficit? Does according autistic self-narrative such a vital, informative role make equal sense on this conception of autistic disabilities? I think not. Indeed, cognitive psychologists who advocate this view have tended to be deeply suspicious of autistic self-narrative on theoretical grounds. That is, they regard autistic autobiographies as a particularly misleading source of information about autistic subjective experience. Why? Because reflecting on or talking about one's own subjective phenomena is reflecting on or talking about mental phenomena, precisely the kind of phenomena that autistic individuals are supposed, by their ToM deficit, to have real trouble understanding (see, for instance, Frith and Happé 1999). Hence, the very kind of reports that might encourage some serious rethinking of the ways in which a theory like the ToM deficit account misleads us as to the thickness of autistic mental life are, by virtue of that self-same deficit account, denied any real credibility. This is why I think the ToM deficit hypothesis is more troubling, and more important to question, than Hacking acknowledges.

\section{Transforming the Autistic Spectrum}

I have yet to comment on the more radical aspect of Hacking's proposal: that this relatively new and thriving genre of autistic self-narrative has the power not just to inform but to transform how the autism spectrum is constituted, both for those who inhabit it and for those who do not. As I said at the outset, I'm sympathetic to this thesis, at least in some respects. But I think there are different ways to understand it, and I have some doubts concerning at least one idea Hacking seems to have in mind. 
So how might this genre of autistic self-narration have the power to transform the autism spectrum, by which I understand Hacking to mean: How will people's experiences with autism change, whether they are themselves autistic, whether they're nonautistic, or perhaps whether they're somewhere in between (we hear and talk a lot at the moment about family members, friends, or colleagues who have "autistic-like" characteristics)?

Here's one possibility that seems likely-in fact, I think there are plenty of signs that this is already happening. As autistic individuals talk and write more about themselves, and as these reflections become more widely disseminated through the medium of print, interview, self-made videos, blogs, and other rich resources now available through the Internet, our interactions with autistic individuals are bound to change in countless ways. This will be true mostly for people who work closely with autistic individuals - parents, caregivers, teachers, therapists, clinicians, social workers, colleagues, and even friends. But it may also be true for the wider public as well, as more room is made in social space for people with a now increasingly familiar suite of atypical behaviours and needs. The "odd" and "strange" and "better off avoided" will become, at least in some respects, more "normal," more accepted, more "worked with" than "worked against."

Of course, this is a slow process, but the practical consequences for autistic individuals will be of enormous importance. As their external environment changes - as it becomes more enriched from the perspective of offering more informed, and hence more suitable, kinds of emotional and physical support, teaching and therapy - so too will their own developmental prospects be transformed. In this autistic individuals are not unlike the rest of us. Their development will depend on the conditions they encounter on the long road to maturity, just as our development depends on the conditions we encounter. If autistic self-narratives have the power to change those conditions for the better, then autistic selfnarratives have the power to transform what it is to be autistic. This idea seems entirely plausible.

However - and this is my last point-Hacking floats another suggestion for how autistic self-narratives can have the power to transform autistic experiences, and about this I'm a little more sceptical. He points (rightly) to the fact that autistic individuals are in touch with one another as never before. The Internet, in particular, provides a wonderful medium for such individuals to learn about one another, to share experiences, to discuss the challenges they face in dealing with neurotypicals and the world in general, and, of course, to form support and advocacy groups. Through all of this, Hacking suggests, norms are emerging - norms that reflect and perhaps constitute a sense of what it is to be autistic.

Now, in ordinary situations, when norms emerge for various ways of being - norms, for instance, concerning what it is to be a friend, or a good 
neighbour, or a patriot - there's a very strong tendency among neurotypical individuals to shape and regulate their attitudes and behaviour in accord with these norms, and thereby to reinforce them. (Hacking has called this a "looping effect" in other writings; in this essay, I call it a susceptibility to "co-mindedness".) As I pointed out earlier, this susceptibility to co-mindedness is, in fact, the way neurotypicals come, in the course of ordinary development, to develop minds at all. But what about autistic individuals? The surprising, even shocking, discovery has been that they have become minded in quite sophisticated ways without ever becoming co-minded, without sharing in our normative ways of being a psychological agent. So this raises a question. How do autistic individuals relate to norms, even norms that emerge (so to speak) in the context of their own discussions?

Words for neutotypical human beings are powerfully social; they are a primary means by which we become and remain co-minded with one another. Will autistic individuals come to relate to words in the same way, as they discover and build a community of others? Will they feel compelled to live up to certain ideas that get expressed of what it is to be autistic? Or will they be less moved, less influenced, by reflections that may in some sense resonate with their own experience, yet fail to suggest to them a normative way of being? In short, will they ever become cominded with one another, or will they just remain differently minded? I don't have strong views about this one way or the other; but I think there's reason to suspect that their relationship to language will never be quite what it is for neurotypicals, even as they develop a language that is more satisfyingly their own. As one such individual, Amanda Baggs, says, "My language is not about designing words or even visual symbols for people to interpret. It is about being in constant conversation with every aspect of my environment" (Baggs 2007). So I end with the following thought: Hacking cautions us about using phrases like "the autistic mind"_- "as if 'the autistic mind' were a species of mind" (2009a, 1470). Ironically, I think this observation may be truer than he suspects-indeed, if I am right, neurotypical minds are more likely to constitute $a$ species of mind; autistic minds are more likely to remain exceptionally multiple and idiosyncratic.

\section{University Center for Human Values}

Princeton University

304 Louis Marx Hall

Princeton, NJ 08544

USA

vmcgeer@princeton.edu 


\section{References}

Asperger, Hans. 1944. "Die autistichen Psychopathen im Kindesalter." Archiv fur Psychiatrie und Nervenkrankheiten 117:76-136.

Baggs, Amanda M. 2007. "In My Language." (Video.) YouTube.

Frith, Uta. 2003. Autism: Explaining the Enigma. Oxford: Blackwell.

Frith, Uta, and Francesca Happé. 1999. "Theory of Mind and SelfConsciousness: What Is It Like to Be Autistic?" Mind and Language 14, no. 1:1-22.

Hacking, Ian. 2009a. "Autistic Autobiography." Philosophical Transactions of the Royal Society B: Biological Sciences 364, no. 1522:1467-73.

—. 2009b. "How We Have Been Learning to Talk About Autism: A Role for Stories." Included in this collection.

Heider, Fritz, and Mary-Ann Simmel. 1944. "An Experimental Study of Apparent Behavior." American Journal of Psychology 57:243-59.

Kanner, Leo. 1943. "Autistic Disturbances of Affective Contact." Nervous Child 2:217-50.

Klin, Ami. 2000. "Attributing Social Meaning to Ambiguous Visual Stimuli in Higher-Functioning Autism and Asperger Syndrome: The Social Attribution Task." The Journal of Child Psychology and Psychiatry and Allied Disciplines 41, no. 7:831-46.

Klin, Ami, Fred R. Volkmar, and Sara S. Sparrow, eds. 2000. Asperger Syndrome. New Haven: Yale University Medical Center.

Mayes, Susan D., and Susan L. Calhoun. 2001. "Non-significance of Early Speech Delay in Children with Autism and Normal Intelligence and Implications for DSM-IV Asperger's Disorder." Autism 5, no. 1:81-94.

Mayes, Susan D., Susan L. Calhoun, and Dana L. Crites. 2001. "Does DSM-IV Asperger's Disorder Exist?" Journal of Abnormal Child Psychology 29, no. 3:263-71.

McGeer, Victoria. 2001. "Psycho-practice, Psycho-theory and the Contrastive Case of Autism." Journal of Consciousness Studies 8, nos. $5-7: 109-32$.

- Forthcoming. "The Skill of Perceiving Persons." The Modern Schoolman.

Ozonoff, Sally, Mikie South, and Judith N. Miller. 2000. "DSM-IVDefined Asperger Syndrome: Cognitive, Behavioral and Early History Differentiation from High-Functioning Autism." Autism 4, no. 1:2946.

Ryle, Gilbert. 1949. The Concept of Mind. Chicago: University of Chicago Press. 